\title{
Synergetic and sliding mode controls of a PMSM: A comparative study
}

\author{
Nourdine Bounasla ${ }^{1, ~}$, Kamel Eddine Hemsas ${ }^{1}$, Hacene Mellah ${ }^{2}$ \\ ${ }^{1}$ Laboratory of Automatic, Department of Electrical Engineering, Ferhat Abbas University Setif-1, Sétif 19000, Algeria \\ ${ }^{2}$ Department of Electrical Engineering, Hassiba Benbouali University Chlef, Chlef 02000, Algeria
}

Email address:

salemtour@gmail.com (N. Bounasla), hemsas.kamel@gmail.com (K. E. Hemsas), has.mel@gmail.com (H. Mellah)

\section{To cite this article:}

Nourdine Bounasla, Kamel Eddine Hemsas, Hacene Mellah. Synergetic and Sliding Mode Controls of a PMSM: A Comparative Study. Journal of Electrical and Electronic Engineering. Special Issue: Sustainable and Renewable Energies and Systems.

Vol. 3, No. 1-1, 2015, pp. 22-26. doi: 10.11648/j.jeee.s.2015030101.13

\begin{abstract}
Permanent magnet Synchronous machines (PMSM) provide high efficiency, compact size, robustness, lightweight, and low noise; these features qualify them as the best suitable machine for medical applications. Without forgetting its simple structure, high thrust, ease of maintenance, and controller feedback, make it possible to take the place of steam catapults in the future. This paper presents the synergetic control approach for PMSM. Synergetic control theory is purely analytical and is based on nonlinear models, provide asymptotic stability. This approach allows to reduce the chattering phenomenon. To verify the performance characteristics of this approach, we compare it with sliding mode. Simulation results are presented to show the effectiveness of the proposed control method.
\end{abstract}

Keywords: PMSM, Synergetic Control, Sliding Mode Control, Asymptotic Stability

\section{Introduction}

In a modern industrialized country about $65 \%$ of electrical energy is consumed by electrical drives. Constant-speed, variable-speed or servo-motor drives are used almost everywhere: in industry, trade and service, house-holds, electric traction, road vehicles, ships, aircrafts, military equipment, medical equipment and agriculture [1]. Permanent magnet (PM) machines provide high efficiency, compact size, robustness, lightweight, and low noise, [2], these features qualify them as the best suitable machine for medical applications [3]. Without forgetting its simple structure, high thrust, ease of maintenance, and controller feedback, make it possible to take the place of steam catapults in the future [4]. The PM motor in an HEV power train is operated either as a motor during normal driving or as a generator during regenerative braking and power splitting as required by the vehicle operations and control strategies. PMSM with higher power densities are also now increasingly choices for aircraft, marine, naval, and space applications [2]. Permanent magnet synchronous motor (PMSM) has been attracting more and more attention in high performance electric drive applications since it has certain superiorities such as; high efficiency, high power factor, superior power density, large torque to inertia ratio and long life over other kinds of motors such as DC motors and induction motors [5]. However, precise control of a PMSM is not easy due to nonlinearities of PMSM servo systems, parameter and load torque variations. Thus the linear control schemes such as PI control cannot guarantee satisfactory performances. To get around this problem, various methods of nonlinear control methods have been developed for PMSM system, such as input-output linearization control [6], robust control [7], sliding mode control [8], back-stepping control [5], and fuzzy control [9] and so on.

Sliding mode control (SMC) [1] attracts the attention of many researchers in the field control of electrical machines has been suggested as an approach for the control of systems with nonlinearities, uncertain dynamics and bounded input disturbances. The most distinguished features of the SMC technique are: insensitivity to parameter variations, external disturbance rejection but the commutations of the control at high frequencies induce chattering problem. This problem can degrade the performance of mechanical systems because it causes excessive energy consumption and reduces the life of mechanical equipment. To remedy this problem, an asymptotic state observer is proposed to limit the chattering [11]. Another solution based on synergetic control is introduced. This command like sliding mode control is based 
on the basic idea that if we could force a system to a desired manifold with designer chosen dynamics using continuous control law, we should achieve similar performance as SMC without its main inconvenient: chattering phenomenon [12-13].

The aim of this paper is to give a comparison between sliding mode control (SMC) and synergetic control (SC) applied on PMSM based drive.

\section{PMSG Model}

The electrical model of PMSM is given by the following equations [14].

$$
\left\{\begin{array}{l}
\frac{d i_{d}}{d t}=-\frac{R_{s}}{L_{d}} i_{d}+\frac{L_{q}}{L_{d}} p \omega+\frac{V_{d}}{L_{d}} \\
\frac{d i_{q}}{d t}=-\frac{R_{s}}{L_{q}} i_{q}-\frac{L_{d}}{L_{q}} p \omega i_{d}-\frac{\phi_{f}}{L_{q}} p \omega+\frac{V_{q}}{L_{q}}
\end{array}\right.
$$

Where $i_{d}$ and $i q$ as state variables and $V_{d} V_{q}$ are control variables.

The expression of the electromagnetic torque and the equation of motion of the rotor are given by the following equations.

$$
\left\{\begin{aligned}
J \frac{d \omega_{r}}{d t} & =T_{e m}-T_{L}-f \omega \\
T_{e m} & =\frac{3}{2} p\left(\phi_{f} i_{q}+\left(L_{d}-L_{q}\right) i_{q} i_{d}\right.
\end{aligned}\right.
$$

\section{Sliding Mode Control}

The sliding mode control algorithm design is to determine three different stages as follow [15]:

\subsection{Commutation Surface}

J. Slotine proposes a general form of equation to determine the sliding surface [16].

$$
s(x, t)=\left(\frac{d}{d t}+\lambda\right)^{r-1} e
$$

$e(t)$ : is variation of the variable to be regulated.

$$
e(t)=x_{r e f}(t)-x(t)
$$

Where $\lambda$ : is positive constant and $r$ : relative degree.

\subsection{Convergence Condition}

The convergence condition is defined by the following Lyapunov equation.

$$
s(x) \dot{s}(x)<0
$$

\subsection{Calculation Control}

The control algorithm includes two terms, the first for the exact linearization, and the second discontinuous one for the system stability.

$$
U=U_{e q}+U_{n}
$$

$U_{e q}:$ is calculated starting from the expression

$$
\dot{s}(x)=0
$$

$U_{n}$ : is given to guarantee the attractively of the variable to be controlled towards the commutation surface. Its simplest equation is given by:

$$
U_{n}=k \operatorname{sgn} s(x) ; k>0
$$

Fig. 1 shows the diagram of the sliding mode control (SMC) of a PMSM supplied by voltage source inverter.

The sliding surfaces are chosen according to the relation of J.Slotine and the output relative degree.

$$
\left\{\begin{array}{c}
s\left(\omega_{r}\right)=\omega_{\text {ref }}-\omega_{r} \\
s\left(i_{q}\right)=i_{\text {qref }}-i_{q} \\
s\left(i_{d}\right)=i_{\text {dref }}-i_{d}
\end{array}\right.
$$

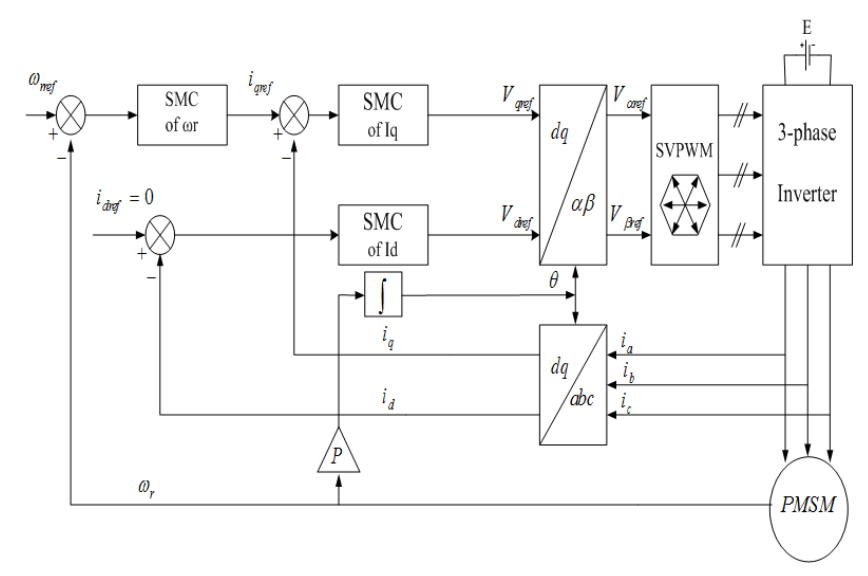

Figure 1. SMC scheme for PMSM.

\section{Synergetic Control Design}

Let us consider an $\mathrm{n}^{\text {th }}$ order nonlinear dynamic system described by (10):

$$
\dot{x}=f(x, u, t)
$$

In which $x$ represents the state vector, $u$ represents the control input vector and $f(x, u, t)$ represents a nonlinear function.

The synergetic controller synthesis procedure is completely analytical, which consists of the following steps [13], [17-18]:

- Start by defining a macro-variable as a function of the state variables, for a dynamical system described by equation (10):

$$
\psi=\psi(x, t)
$$


The control will force the system to operate on the manifold $\psi=0$. The designer can select the characteristics of this macro-variable according to the control specifications (e.g. limitation in the control output, and so on). In the trivial case, the macro-variable is a simple linear combination of the state variables.

- Repeat the same process defining as many macro-variables as control channels.

- Fix the dynamic evolution of the macro-variables according to the equation:

$$
T \dot{\psi}+\psi=0, T>0
$$

$T$ : designates the designer chosen speed convergence to the desired manifold. Differentiating the macro-variable (11) along (10) leads to (13):

$$
\dot{\psi}=\frac{d \psi}{d x} \dot{x}
$$

Combining equation (10), (12) and (13), we thus obtain:

$$
T \frac{d \psi}{d x} f(x, n, t)
$$

- Synthesize the control law (evolution in time of the control output) according to equation (14) and the dynamic model of the system, leads to (15):

$$
u=u(x, \psi(x, t), T, t)
$$

From (15), it can be seen that the control output depends not only on the system state variables, but also on the selected macro-variable and time constant $T$.

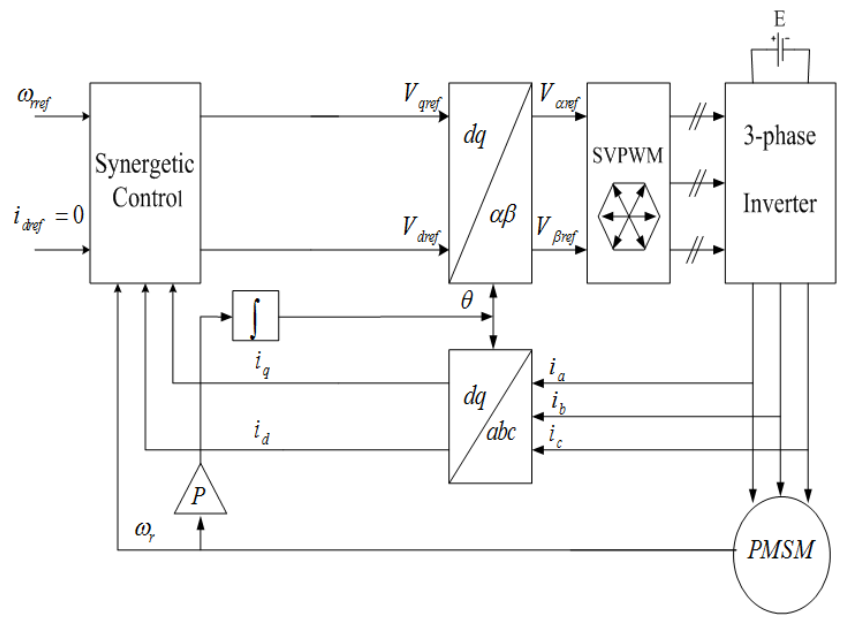

Figure 2. SC scheme for PMSM.

In other words, the designer can choose the characteristics of the controller by selecting a suitable macro-variable and a time constant $T$.

The procedure summarized above can be easily implemented as a computer program for automatic synthesis of the control law. Moreover, the synergetic control system can be global stability, parameters insensitivity and noise suppression by suitable selection of macro-variables.

The method described in the previous paragraph requires that we define the same number of macro-variables as control channels in the system. Thus, it requires the definition of two macro-variables, which are functions of the state variables as shown in (11). We chose these two terms:

$$
\left\{\begin{array}{l}
\psi_{1}=i_{d}-i_{\text {dref }} \\
\psi_{2}=\left(\dot{\omega}_{r}-\dot{\omega}_{r r e f}\right)-k\left(\omega_{r}-\omega_{r r e f}\right)
\end{array}\right.
$$

Where $k$ is controller parameters.

Fig. 2 shows the diagram of the synergetic control (SC) of a PMSM.

\section{Simulation Results}

The performances of the proposed controls were tested by simulation on a $1.5 \mathrm{kw}$ PMSG whose parameters are given in the appendix.

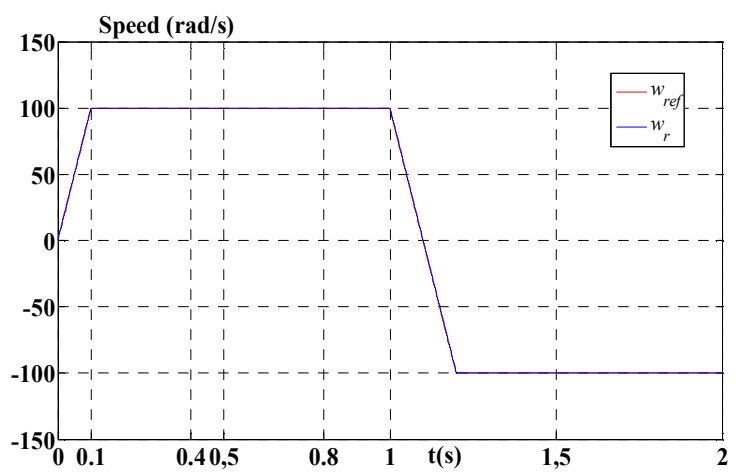

(a) sliding mode control.

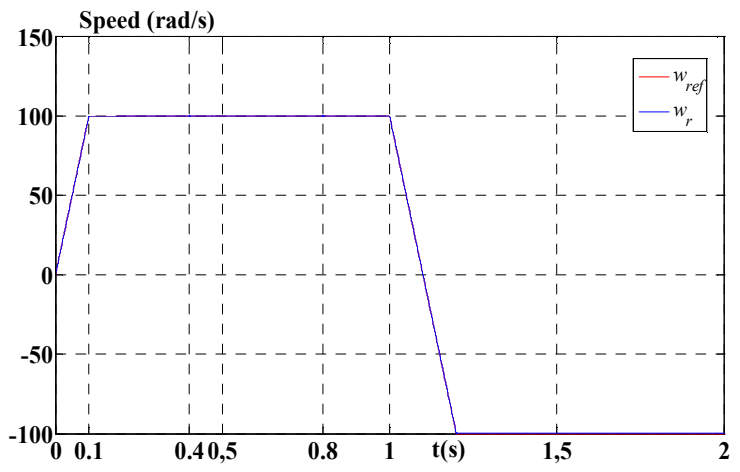

(b) synergetic control

Figure 3. Speed responses of a PMSM controlled by sliding mode and synergetic.

The simulation results are obtained on the Matlab Simulink environment.

The following figure shows the speed curve of a PMSG controlled by sliding mode and synergetic technics, in this figure we can see that the robustness tests are applied for the two controllers.

However, a moderate vibration on the case of the synergetic controller of a magnitude less than 1 N.m. we think 
that the cause of these electromagnetic torque oscillations is the chattering phenomenon.

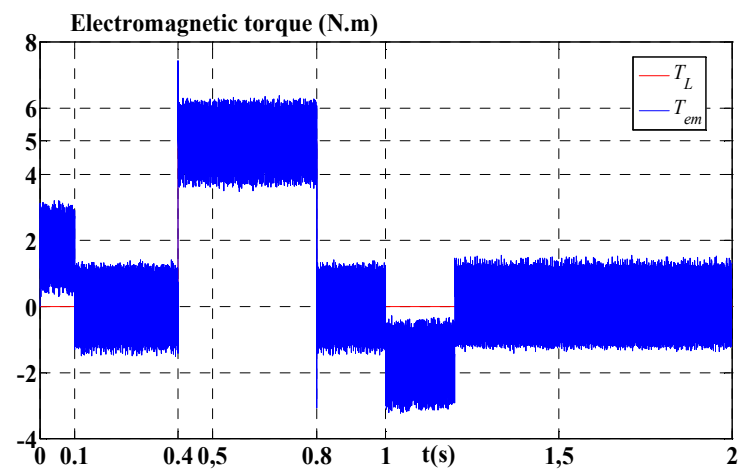

(a) sliding mode control

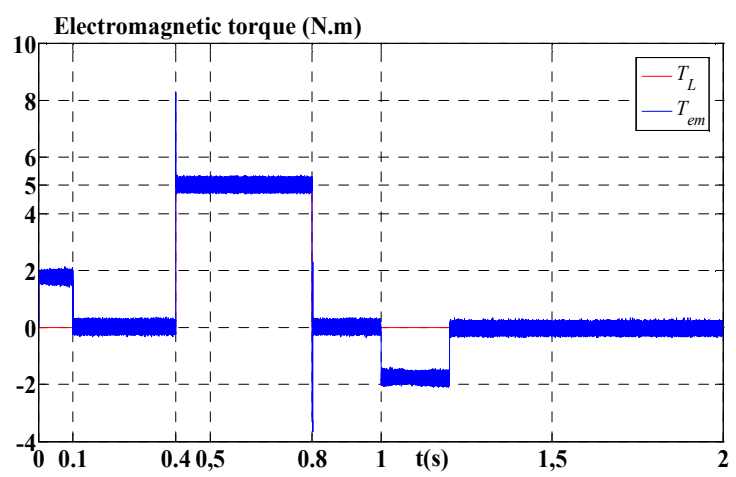

(b) synergetic control

Figure 4. Electromagnetic torque curve of a PMSM controlled by sliding mode and synergetic.

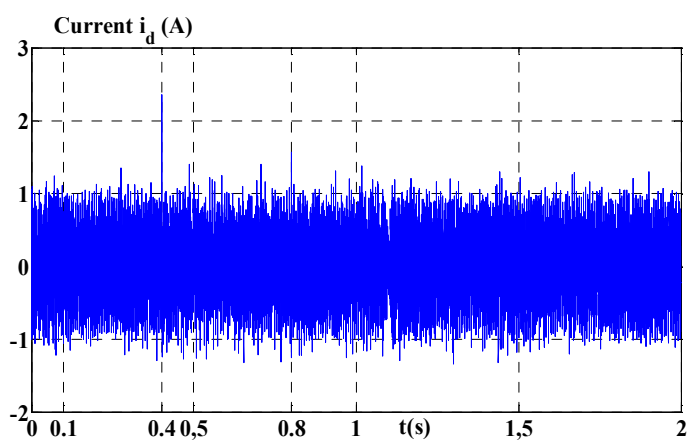

(a) sliding mode control.

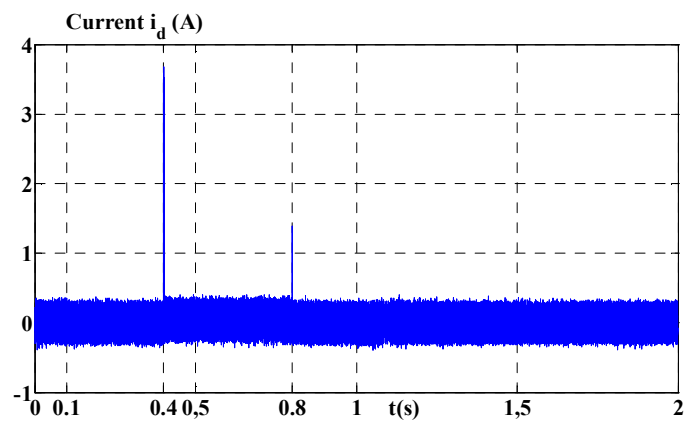

(b) synergetic control

Figure 5. id curve of a PMSM controlled by sliding mode and synergetic.
The $i d$ variations are illustrate in the following figure both for the sliding mod and synergetic controllers, we can see that the id oscillations at the sliding mode case are more important that the synergetic case.

The $i q$ variation of a PMSG controlled by sliding mode and synergetic technics are presented on the fig.6, by comparison between the results of application of the two controllers on the iq current wave, we see an important oscillation on the case of sliding mode controller compared with synergetic controller.

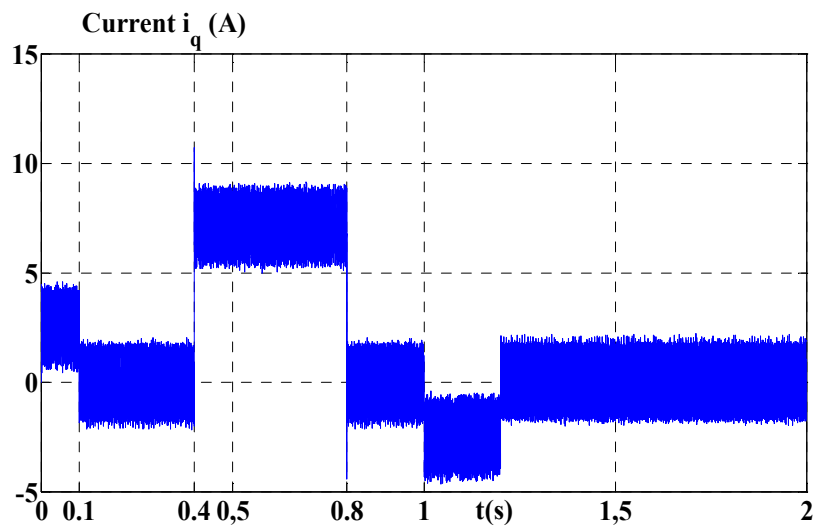

(a) sliding mode control.

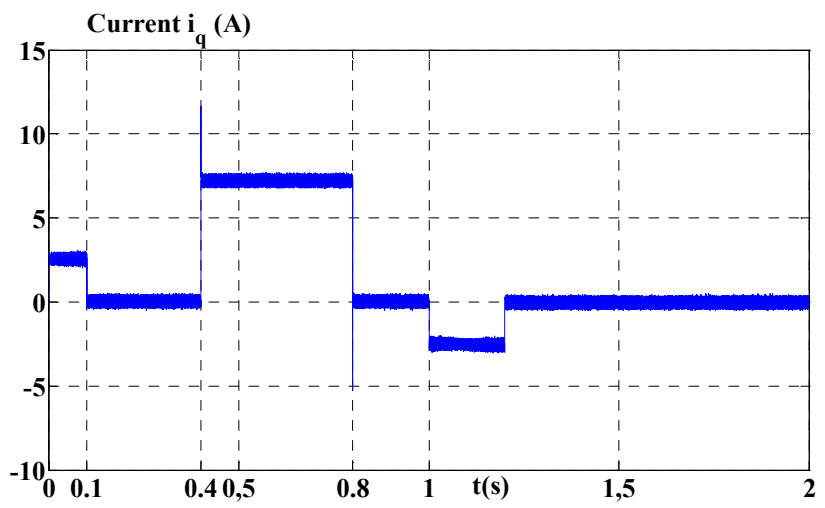

(b) synergetic control

Figure 6. iq curve of a PMSM controlled by sliding mode and synergetic.

\section{Conclusion}

In this paper two different control of permanent magnet synchronous machine (PMSG) are presented. It is a matter of sliding mode control and synergetic control. To compare their performance, many tests are performed under the same conditions.

Simulations results show that the speed and the current id follow perfectly their references. The response of the electromagnetic torque and the current in both cases are compared. It is clear that the synergetic control reduces the chattering better than the sliding mode control.

Simulation results show clearly the effectiveness of the synergetic control in reducing chattering problem. 


\section{Nomenclature}

$V_{d}, V_{q} \quad$ Direct-and quadrature-axis stator voltages.

$i d$, iq Direct-and quadrature-axis stator current.

$L_{d}, L_{q} \quad$ Direct -and quadrature-axis inductance.

$p \quad$ Number of poles.

$R_{s} \quad$ Stator resistance.

$\phi_{f} \quad$ Rotor magnet flux linkage.

$\omega_{r} \quad$ Mechanical rotor speed.

$J \quad$ Inertia.

$f \quad$ Damping coefficient.

$T_{e m} \quad$ Electromagnetic torque.

$T_{L} \quad$ Load torque.

\section{Appendix}

Table 1. PMSM Parameters

\begin{tabular}{ll}
\hline Components & Values \\
\hline Rs & $1.4 \Omega$ \\
$\mathrm{Ld}$ & $0.0066 \mathrm{H}$ \\
$\mathrm{Lq}$ & $0.0058 \mathrm{H}$ \\
$\psi_{f}$ & $0.1546 \mathrm{~Wb}$ \\
$\mathrm{f}$ & $38.818 \mathrm{e}-5 \mathrm{Nm} / \mathrm{rad}$ \\
$\mathrm{J}$ & $1.76 \mathrm{e}-3 \mathrm{~kg} . \mathrm{m} . \mathrm{s}$ \\
$\mathrm{p}$ & 3 \\
$\mathrm{TL}$ & $5 \mathrm{Nm}$ \\
\hline
\end{tabular}

\section{References}

[1] F. JACEK, Permanent Design and Applications," Second Edition, Revised and Expanded United Technologies Research Center Hartford, Connecticut London, United Kingdom 2002.

[2] H. Mellah, K E. Hemsas, "Dynamic Design and Simulation Analysis of Permanent Magnet Motor in Different Scenario of fed Alimentation," Journal of Electrical and Control Engineering (JECE), pp. 55-61, Vol.3, No.4, 2013.

[3] A. Nasiri, Salaheddin A. Zabalawi, and Dean C. Jeutter, "A Linear Permanent Magnet Generator for Powering Implanted Electronic Devices," IEEE transactions on power electronics, pp. 192-199, vol. 26, no. 1, Jan. 2011.

[4] L. Li, H. Junjie, L. Zhang, Y. Liu, S. Yang, R. Liu, L. Xiaopeng, "Fields and Inductances of the Sectioned Permanent-Magnet Synchronous Linear Machine Used in the EMALS," IEEE Transactions on Plasma Science, pp. 87-93, Vol. 39, 2011.

[5] M. Karabacak , H.I. Eskikurt,“ Design, modeling and simulation of a new nonlinear and full adaptive Backstepping speed tracking controller for uncertain PMSM," Applied Mathematical Modelling, vol. 36, no. 11, pp 5199-5213, 2012.
[6] B. Grcar, P. Cafuta, M.Znidaric, and F.Gausch, "Nonlinear control of synchronous servo drive," IEEE Trans. on Control Systems and Technology, vol. 4, no. 2, pp. 177-184, 1996.

[7] T.L. Hsien, Y.Y. Sun and M.C. Tai, "H1 control for a sensorless PMSM drive," IEE Proc. of Electric Power Applications, vol. 144, no. 3, pp. 173-181, 1997.

[8] R.J. Wai, "Total sliding-mode controller for PM synchronous servo motor drive using recurrent fuzzy Neural network," IEEE Trans. on Industrial Electronics, vol. 8, no. 5, pp. 926-944, 2001.

[9] Y.S. Kung and M.H.T sai, "FPGA-based speed control IC for PMSM drive with adaptive fuzzy control," IEEE Trans. on Power Electronics, vol. 22, no. 6, pp. 2476-2486, 2007.

[10] F. Benchabane, "Robust position and speed estimation algorithms for permanent magnet synchronous drives," European Journal of Scientific Research, vol. 57 no. 1, pp. 6-14, 2011.

[11] A.G. Bondarev, S.A. Bondarev, N.Y. Kostyerva, and V.I. Utkin, "Sliding modes in systems with asymptotic state observers," Automation and Remote Control, vol. 46, no. 6, pp. 679-684, 1985.

[12] L. Medjbeur and M.N. Harmas, “Adaptive Fuzzy Terminal Synergetic Control," IEEE Communications, Computing and Control Applications (CCCA), pp. 1-16, 2011.

[13] Z. Bouchama, and M.N. Harmas, "Optimal robust adaptive fuzzy synergetic power system stabilizer design," Elsevier, Electric Power Systems Research, vol. 88, pp. 9-15, 2012.

[14] G. Sturtzer, and E. Smigiel, "Modélisation et commande des moteurs triphasés," Edition Ellipes, 2000.

[15] A. Massoum, M.K. Fellah ,A. Meroufel , P. Wira, and B. Bellabes, "Sliding mode control of a permanent magnet synchronous machine fed by a three levels inverter using a singular perturbation decoupling," Journal of Electrical and Electronic Engineering, vol. 5, no. 2, pp. 1427-1433, 2005.

[16] J. J. Slotine, and W. Li, "Applied non linear control," Prentice-Hall, 1991.

[17] L.E. Santi, A. Monti, D. Li, K. Proddutur, and R. Dougal "Synergetic Control for DC-DC Boost Converter: Implementation options", IEEE Transactions on Industry Applications, vol. 39, no. 6, pp. 1803-1813, 2003.

[18] A. Kolesnikov, G. Veselov, A. Kolesnikov, A. Monti, F. Ponci, E.Santi, and R. Dougal, "Synergetic Synthesis of DC-DC Boost Converter Controllers: Theory and Experimental Analysis," Proc. IEEE APEC, vol. 1, pp. 409-415, 2002. 